\title{
Influence of the Natural Medium on the Hydrocarbons and Fatty Acids Producing from the Microalgae Batryococcus braunii
}

\author{
Gaukhar K. Bishimbayeva, Adilzhan K. Adamgaliyev, and Sandugash K. Kazybekova
}

\begin{abstract}
Algologically pure culture of microalgae Botryococcus braunii was obtained from Alakol Bay of Balkhash Lake. The ability of the selected cultures to synthesize liquid hydrocarbons and fatty acids was revealed. The composition of the lipid compound of investigated microalgae depending on the composition of natural medium was established. Hydrocarbon composition of obtained biomasswas identified, presented mainly by n- alkanes $\mathrm{C21}$ C38, which constitute 41-62 \% of their total number. Fatty acid composition of intracellular and extracellular lipids is represented by saturated, monounsaturated and diene fatty acids of the C12-C24 composition in the ratio of 32:18:38, respectively, indicating the potential for using of this microalgae as raw material forbiodiesel.
\end{abstract}

Index Terms-Botryococcus balkachicus, microalgae, biomass, biofuels.

\section{INTRODUCTION}

Currently in the world there is an acute shortage of energy resources due to depletion of mineral resources. Among renewable raw materials, unicellular biomass can be an alternative to the mineral resources. It was determined that microalgae have significant potential to replace fossil energy resources in the future [1]-[3].

Among unicellular cultures much interest generates an exceptional form, capable of producing hydrocarbons in high proportions-unicellular green alga Botryococcus braunii [4]-[7]. In this widespread green alga that inhabits in freshand brackish water of temperate and tropical zones, hydrocarbons, depending on the growing conditions and diversity of species can constitute up to $75 \%$ of dry mass [8]-[13]. They accumulate inside the cells and microalgae that contains a lot of them float on the water surface. Due to its ability to form lipids in significant amounts, which consist primarily of hydrocarbons similar to petroleum hydrocarbons, species of Botryococcus braunii have an essential role for the production of biofuels. Last decade has witnessed increasing interest in the development of technologies based on the use of renewable raw materials,

Manuscript received December 8, 2013; revised February 10, 2014. The research is conducted as part of the Ministry of Education and Science of the Republic of Kazakhstan' program of grant funding for scientific research under priority: Sources of Renewable Energy.

Gaukhar K. Bishimbayeva and Adilzhan K. Adamgaliyev are with the D. V. Sokolsky Institute of Organic Catalysis and Electrochemistry and Kazakh - British Technical University, Almaty, 050000 Kazakhstan (e-mail bigauhar@mail.ru, aadamgali@gmail.com).

Sandugash K. Kazybekova is with the Institute of the Plant Biology and Biotechnology, Almaty, 050000 Kazakhstan (e-mail: sanflai@mail.ru). including obtaining of the environmentally friendly fuel [14]-[18].

There are several varieties of $B$. braunii that are differentiated by pigmentation and structure of the synthesized hydrocarbons. Green species contains linear hydrocarbons with odd $\mathrm{C} 25-\mathrm{C} 31$ number of carbon atoms with small amount of double bonds. Red alga contains hydrocarbons with C34-C38 carbon atoms and several double bonds, the so-called "botryococcenes". Numerous studies have clearly established that this type of culture have three races: the A, B and $\mathrm{L}$. Microalgae of A race produce n-alkadienes and trienes with odd number of carbon atoms in the chain C23-C33 [4], B-race produce hydrocarbons consisting of triterpenoids and C30-C37 botryococcenes [9] and methylate squalene C31-C34 [19], [20], L race produces monotetraterpenoid hydrocarbons and likopadiens [21].

Today 15 species of microalgae Botryococcus are known, 12 of them identified as taxonomic: $B$. australis, $B$. balkachicus, B. braunii, B. calcareous, B. canadensis, $B$. comperei, B. coorongianus, B. fernandoi, B. giganteus, $B$. neglectus, B. pila, B. protuberans, B. sudeticus, B. terribilis, B. terricol [22]. Alga Botryococcus balkachicus [23] abundantly grows in Kazakhstan at Alakul bay of Balkhash Lake, and carbohydrate content of the culture is so high that it floats on the water surface, forming a combustible material on the shore with a calorific capacity comparable to that of oil [24]. In natural samples of Botryococcus braunii, hydrocarbon content can be up to $70 \%$ of lipids, and most of them are synthesized in the period of active growth and is localized in the matrix of the colony. Structure of Botryococcus braunii depends on the strain features of the organism, and their output is believed to be also depend on growing conditions [25]-[27].

The aim of this work is to allocate algological pure culture of the Botryococcus balkachicus from the Alakul Bay sample of Balkhash Lake, its cultivation in conditions closest to the natural, as well as studying of the component composition of the biomass of pure natural culture - fatty acid and hydrocarbon. In this regard, the fatty acids and the structure of hydrocarbons of this type of natural culture were identified.

\section{Methodology OF THE EXPERIMENT}

\section{A. Algal Strain and Culture Conditions}

Objects of the research are culture of algae colonies Botryococcus braunii, allocated from the water samples of Alakul Bay, Balkhash Lake. Biomass was grown on the 
basis of the natural media (lake water from the bay Alakol, Balkhash Lake).

To get culture of algae Botryococcus braunii, crop of samples from water samples of Alakul Bay, Balkhash Lake into liquid nutrient media was conducted, diluted $(1: 10)$ with the following seeding on the nutrient media until algological pure cultures were obtained. For enrichment of the culture, seeding was carried out in $250 \mathrm{ml}$ in volume sown conical flask with liquid nutrient medium. The medium was prepared based on sterile water from the reservoir, where investigated algae was collected, as well as diluted in a ratio of $1: 2$ to $1: 5$. Inoculated cultures of algae were grown in sterile conditions under illumination of 2000$5000 \mathrm{Lux}$, and $26{ }^{\circ} \mathrm{C}$ in photoperiod regime $12 \mathrm{~h} / 12 \mathrm{~h}$. Culture was continuously aerated with the mixture of air with $1 \%$ content of $\mathrm{CO}_{2}$. For obtaining algological pure culture and its reproduction onto fresh nutrient media, algae Botryococcus braunii colonies from a single cell were selected, marked on the Petri cup and reseeded several times.

\section{B. Sample Preparation for Analysis}

To examine the composition of fatty acids and hydrocarbons, filtering of the suspension culture of algae cells Botryococcus braunii was conducted, followed by drying to a constant weight. The resulting slurry with biomass was centrifuged in Falcon tubes with the speed of 6000 turnover/Min at a temperature of $35^{\circ} \mathrm{C}$. To the residue $1 \mathrm{ml}$ of water was added and weight was measured by deducting the weight of pre-weighed tubes. The precipitate was freeze- dried at a temperature of $80{ }^{\circ} \mathrm{C}$ for 12 hours and then weighed. The dry biomass was dissolved in $30 \mathrm{ml}$ of hexane and extracted on ultrasonic bath Sonycation system Bandelin Sonorex (Germany) by ultrasound cleavage for 30 minutes. The suspension was filtered and the hexane solution was evaporated to dryness at $30{ }^{\circ} \mathrm{C}$ under nitrogen current. Next, the precipitate was dissolved in $5 \mathrm{ml}$ of hexane, the resulting solution hydrocarbons were separated from fatty acids by method of column chromatography on active aluminum oxide using hexane as eluent. After washing of the column with hexane, lipid portion was washed off with three portions of the chloroform: methanol $(1: 2,1: 1,2: 1)$. The resulting solution of lipids in chloroform: methanol methylated with $2 \mathrm{M}$ solution of sodium methylate.

Hence, for the study of fatty acid and hydrocarbon composition of biomass sample of Botryococcus balkachicus, samples were obtained based on three variants of Lake Media from Alakul Bay,Balkhash Lake, differing in concentrations, for the three samples, respectively:

Sample 1: sample obtained on the basis of natural media of the lake water;

Sample 2: sample obtained on the basis of the lake water with $1 / 2$ times dilution;

Sample 3: sample obtained on the basis of the lake water with $1 / 5$ times dilution.

\section{Gas-Chromatographic Method of Analysis of Fatty Acids}

The composition of fatty acids in the form of their methyl esters was examined using gas-chromatography method on the gas chromatograph GC-2010 ("SCIMADZU", Japan). Chromatographic conditions: gas carrier - nitrogen, flow rate - $0,048-0,072 \mathrm{dm} / \mathrm{g}$, the temperature of detector -200$250^{\circ} \mathrm{C}$, the temperature of the evaporator $120-200^{\circ} \mathrm{C}$, the initial temperature of chromatography $-70^{\circ} \mathrm{C}$, pressure $150 \mathrm{kPa}$, speed - 15 to $220 \mathrm{ml} / \mathrm{min}$.

\section{Gas Chromatography Method with Mass Spectrometric Detection}

To determine the hydrocarbon composition of the obtained biomass by cultivating a pure culture in the natural media, analysis on gas chromatography with mass spectrometric detection 7890A/5975S (Agilent, USA) was conducted. $1 \mathrm{mcl}$ of hexane extracts using Combi-PAL (CTC Analytics AG, Switzerland) autosampler was injected into a gas chromatograph evaporator, heated to a temperature of $280{ }^{\circ} \mathrm{C}$ in the splitless flowmode. Separation was performed on a column DB-5MS (Agilent, USA) with a length $60 \mathrm{~m}$, internal diameter $0.25 \mathrm{~mm}$, film thickness 0.25 $\mathrm{mkm}$ at a constant flow rate of gas-carrier (helium grade "A") of $1 \mathrm{ml} / \mathrm{min}$. Temperature of column thermostat was programmed from $50{ }^{\circ} \mathrm{C}$ (hold for 1 minute) to $310{ }^{\circ} \mathrm{C}$ at a heating rate of $10^{\circ} \mathrm{C} / \mathrm{min}$, with exposure for 30 minutes. Full time of analysis was $57 \mathrm{~min}$. Mass spectrometric detection was performed in the registration mode of the total ion current in the range of mass numbers 34-400, the delay of the solvent was 8 minutes, the interface temperature was $310{ }^{\circ} \mathrm{C}$, temperature of the ion sources was $230{ }^{\circ} \mathrm{C}$, of the quadrupole $150{ }^{\circ} \mathrm{C}$. The data were processed using MSD ChemStation software. Peaks in the chromatograms were identified by their mass-spectra with the use of digital libraries NIST'08 and Wiley, $8^{\text {th }}$ edition. For all samples, the curves of simulated distillation were constructed according to the ASTM D2887 method until $510{ }^{\circ} \mathrm{C}$ temperature. The calibration dependence of the boiling temperature from the point of retention was obtained by analyzing a mixture of normal alkanes. The processing was performed in Microsoft Excel 2013 software.

\section{RESULTS OF EXPERIMENT}

Analysis of the impact of the media on the group distribution of fatty acids (see Table I) shows that in the natural media of the lake, intracellular and extracellular lipids are represented mainly by saturated (30 - 39\%) and diene unsaturated (39-45\%), to a lesser extent-by monounsaturated (12-18\%) and a small proportion (3-12\%) of triene fatty acids. It should be noted that in a medium that was diluted 5 times, the proportion of mono-unsaturated acids significantly increases as a result of reduction in the proportion of diene fatty acids.

Tables I and II show the data of the respective chromatograms of intra-and extracellular fatty acids allocated as a result of cultivation of the algae Botryococcus braunii on the natural lake media of the Alakul Bay of Balkhash Lake for different concentrations that are shown in Fig. 1-Fig. 6.

The fatty acid composition of the intercellular lipids in all three media is presented by saturated acids with long chain from 11 to 24 , where in the proportion of saturated fatty acid ranges from $25 \%$ to $39 \%$ from total number of intracellular fatty acids (see Table II). 
TABLE I: DISTRIBUTION OF THE FATTY ACIDS BY GROUPS

\begin{tabular}{|c|c|c|c|c|c|c|}
\hline \multirow[t]{3}{*}{ Groups of FattyAcids, $\%$} & \multicolumn{6}{|c|}{ (\% of the sum of fatty acids) } \\
\hline & \multicolumn{2}{|c|}{1 sample (1) } & \multicolumn{2}{|c|}{2 sample $(1 / 2)$} & \multicolumn{2}{|c|}{3 sample $(1 / 5)$} \\
\hline & intra & extra & intra & extra & intra & extra \\
\hline Saturated & 39,13 & 30,85 & 25,82 & 25,82 & 25,193 & 25,656 \\
\hline Monoenic & 18,68 & 12,24 & 18,71 & 18,71 & 69,504 & 54,329 \\
\hline Diene unsaturated & 38,80 & 44,75 & 49,53 & 49,53 & 5,303 & 20,015 \\
\hline Triene unsaturated & 3,39 & 12,17 & 3,29 & 3,29 & 0,00 & 0,00 \\
\hline Tetraenoic & 0,00 & 0,00 & 0,00 & 0,00 & 0,00 & 0,00 \\
\hline
\end{tabular}

TABLE II: FATTy ACID COMPOSITION OF LiPIDS OF SAMPLE B. BRAUNII, ALLOCATED FROM LAKE WATER OF ALAKUL BAy, BALKHASH LAKE (\% OF

\begin{tabular}{|c|c|c|c|c|c|c|}
\hline & & & TTY ACIDS) & & & \\
\hline Compounds & & sample (1) & & $(1 / 2)$ & & mple (1/5) \\
\hline & intra & extra & intra & intra & extra & intra \\
\hline $\mathrm{C} 11: 0$ & 5.6545 & & & & & \\
\hline $\mathrm{C} 12: 0$ & 0.9925 & & & & & \\
\hline $\mathrm{C} 14: 0$ & 2.0611 & & 1.9938 & 3.4564 & & \\
\hline $\mathrm{C} 15: 0$ anteizo & & & & 0.6796 & & \\
\hline C15:0 & & & & 0.7279 & & \\
\hline C16:0 & 20.1627 & 15.4763 & 14.6433 & 17.3649 & 4.404 & 7,297 \\
\hline C16:0 izo & & & & 0.1664 & & \\
\hline C16:1w9 & & & 2.6595 & 1.6189 & & \\
\hline C16:1w7 & & & & 0.6930 & & \\
\hline C17:0 anteizo & & & & 0.3342 & & \\
\hline $\mathrm{C} 17: 0$ & & & & 0.4549 & & \\
\hline C17:1w7 & & & 0.9037 & & & \\
\hline C18:0 & 10.2576 & 8.7420 & 5.6489 & 7.9932 & 9.037 & 19,024 \\
\hline C18:1w7 & 2.5721 & & & 2.3518 & & \\
\hline C18:1t9 & & & & & 23.109 & 27,520 \\
\hline C18:1w6 & & & & & 1.618 & 2,171 \\
\hline C18:1w11 & & & & & 1,487 & 2,151 \\
\hline C18:1w12 & & & & & 2.577 & 4,477 \\
\hline $\mathrm{C} 18: 2 \mathrm{t}$ & & & & & 2.561 & 2,517 \\
\hline C18:2w 9,t12 & & & & & 0,833 & 1,430 \\
\hline C18:2 w 9,12 & & & & & 1,085 & 5,002 \\
\hline C18:2 w12,15 & & & & & 0,279 & 0,591 \\
\hline C18:1w9 & 14.4984 & 12.2360 & 15.3689 & 18.5772 & 29.544 & 45,512 \\
\hline C19:0 & & & 3.5310 & & & \\
\hline C18:2w6 & 38.7984 & 44.7487 & 49.5265 & 36.4085 & & \\
\hline C18:3w2 & & & & & & 11,489 \\
\hline C18:3w6 & & & 1.2176 & 0.4843 & & \\
\hline $\mathrm{C} 18: 3 \mathrm{w} 3$ & & & & 0.8339 & & \\
\hline $\mathrm{C} 20: 0$ & & 6.6268 & & & 0,627 & 0,995 \\
\hline $\mathrm{C} 20: 1$ & & & & & 0,515 & 0,748 \\
\hline $\mathrm{C} 20: 2$ & & & & & 0,558 & \\
\hline C20:1w9 & 1.6079 & & 4.2457 & 1.6749 & & \\
\hline $\mathrm{C} 20: 3 \mathrm{w} 3$ & 3.3949 & 12.1703 & 2.0684 & 1.9711 & & \\
\hline $\mathrm{C} 22: 0$ & & & & 0.6530 & 0,778 & 0,574 \\
\hline $\mathrm{C} 22: 2$ & & & & 1.3105 & & \\
\hline C23:1 & & & & 2.2455 & & \\
\hline C20:3 w1 & & & & & 0,881 & \\
\hline C24:0 & & & & & & 0,853 \\
\hline C24:1 & & & & & 0,512 & \\
\hline
\end{tabular}


As a dominant intracellular saturated fatty acids palmitic (C16:0) and stearic (C18:0) were identified, where in with the dilution of the medium their content decreases from $20 \%$ in the sample 1 to $4.4 \%$ in sample 3 . Among monoenoic acids in a significant amount ( 14.5 to $29.5 \%$ ) octadecenoic (oleic) acid

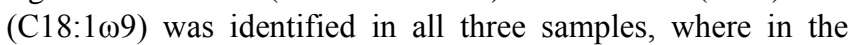
third sample, which was diluted 5 times- almost twice as much as in the first two samples. Moreover, a small amount of octadecenoic acid isomer was detected in sample 1 (C18:1 $\omega 7)$, in sample 3, four of its isomer were identified (C18:1t9, $\mathrm{C} 18: 1 \omega 6, \mathrm{C} 18: 1 \omega 11, \mathrm{C} 18: 1 \omega 12)$, as well as eicosenoic (C20:1) and tetracozenic $(\mathrm{C} 24: 1)$ acids in the sample 3 . In the regards of dienic acid, it should be noted that for samples 1 and 2, a high content of isomer of octadecadienoic acid $(\mathrm{C} 18: 2 \omega 6)$ to $38-49 \%$ of total fatty acids are typical, where as sample 3 revealed the formation of a small content of four isomers of

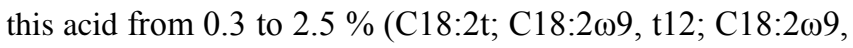

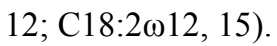

Extracellular fatty acid are represented by acids with the carbon atoms in the chain from $\mathrm{C} 14$ to $\mathrm{C} 24$, saturated fatty acid fraction constitute $28 \%-30 \%$ of total extracellular fatty acids. Besides, as in the case of intracellular lipids among saturated fatty acids, hexadecanoic (palmitic acid) (C16:0) and octadecanoic (stearic), (C18:0) acids are predominant, while among monounsaturated, the content of octadecenoic (oleic) acid (C18: 109) increases with the dilution of the medium, $12.24 \%$ in the lake water, diluted 2-times $-18.58 \%$, diluted 5-times in a medium-45.54\% (from the total number of extracellular fatty acids). Moreover, extracellular diene fatty acids were identified, whose content (C18: 206) in samples 1 and 2 reaches $44.75 \%$, and $36.41 \%$, respectively. Furthermore, in samples 1 and 3 the extracellular triene fatty acid a represent

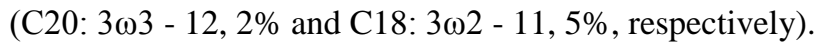

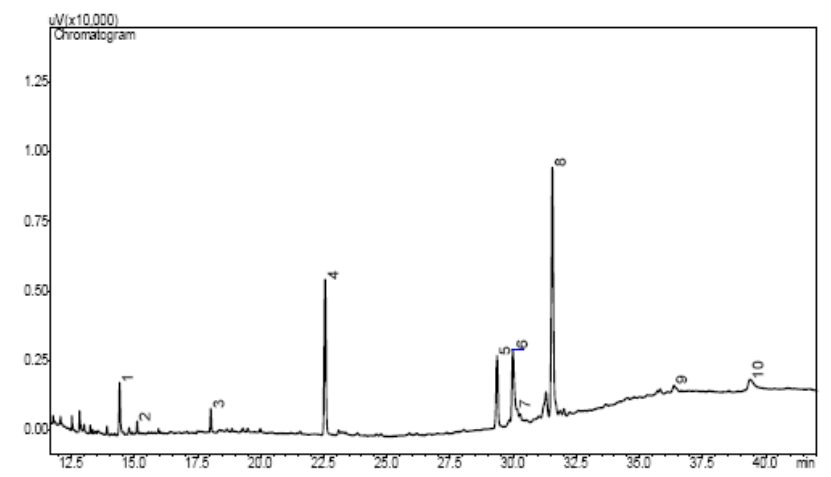

Fig. 1. The chromatogram of intracellular fatty acids, allocated from the sample B. braunii in the natural water media of Balkhash Lake (Sample 1).

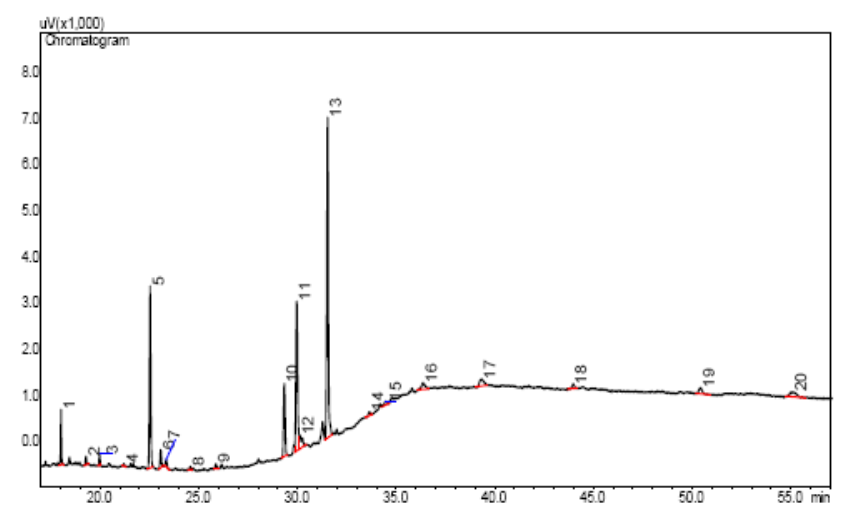

Fig. 2. The chromatogram of intracellular fattyacids allocated from sample B.braunii in the natural water media of Balkhash Lake with $1 / 2$ dilution (Sample 2).

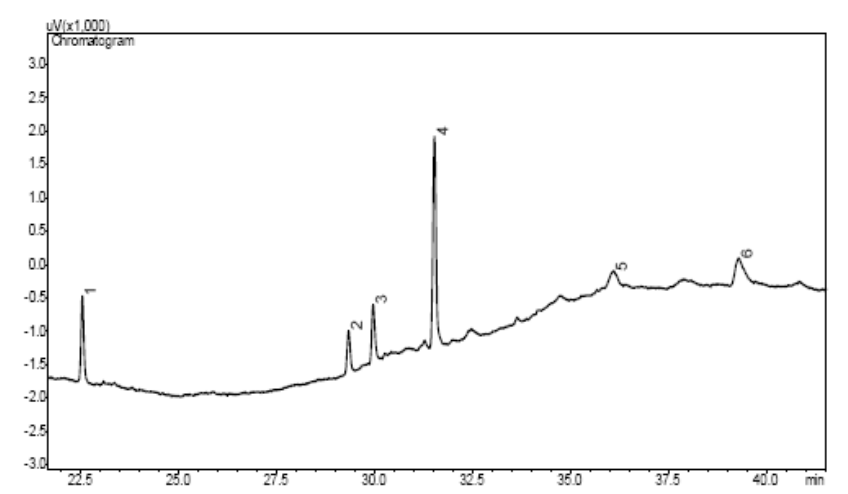

Fig. 3. Chromatogram of extracellular fatty acids allocated from the sample B.braunii in the natural water media of Balkhash Lake (Sample 1).

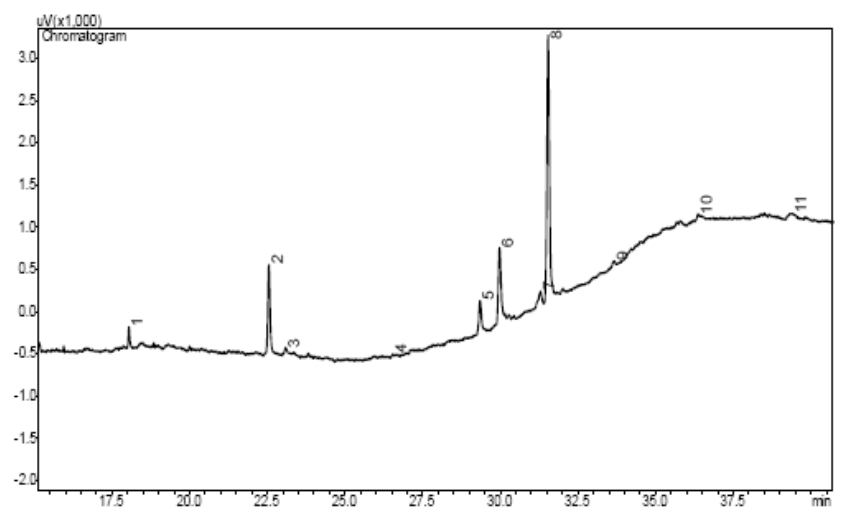

Fig. 4. The chromatogram of extra cellular fatty acids allocated from sample B.braunii in the natural water media of Balkhash Lake with 1/2 dilution (Sample 2).

Analysis of the fatty acid composition of the lipids of B.Braunii sample, allocated from water of Alakul Bay, Balkhash Lake, indicated that the content of intracellular lipid depending on the medium constitute $11.2 \%-19.8 \%$ of dry weight. Hydrocarbons B. braunii are of interest for the production of biofuels. They can be used in the process of hydrocracking, most easily converted into fuel. The hydrocarbon composition can reach $27 \%-86 \%$ of the dry weight of the cells. Hydrocracking leads to the following values: $67 \%$ of the gasoline fraction, $5 \%$ of kerosene and $15 \%$ of diesel [27].

To determine the hydrocarbon composition of the biomass obtained as a result of cultivation of a pure culture in the natural media of the lake, group analysis was performed using the method of gas chromatography with mass spectrometric detection. Table III shows the identification of the hydrocarbon based on group composition. To determine separate classes of hydrocarbons, we used signals of their characteristic ions on the mass spectra that were recorded at each point in the chromatogram, as shown in Fig. 7-Fig. 12.

Analysis of the relative content of hydrocarbons shows that the fraction of liquid hydrocarbons in all considered embodiments of the lake water media, depending on the composition, constitute $30-39 \%$ of total lipids. Intracellular hydrocarbon composition represented mainly by paraffin (42-62\%), non-condensed cycloparaffin (up to $12 \%$ ) depending on the medium composition. Production of intracellular hydrocarbons of the considered algae almost 23 times higherthan that of intracellular, depending on the composition of the medium. Thus, for undiluted lake water, maximum ratio of intracellular to extracellular hydrocarbons 
(62.2/21.2) was observed, namely 2.9. Extra cellular hydrocarbons almost equally represented by paraffins, condensed and noncondensed cycloparaffin with two and three rings.

TABLE III: GROUP HYDROCARBON COMPOSITION

\begin{tabular}{|c|c|c|c|c|c|c|}
\hline \multirow[b]{2}{*}{ Hydrocarbons } & \multicolumn{2}{|c|}{1 sample (1), \% } & \multicolumn{2}{|c|}{2 sample $(1 / 2), \%$} & \multicolumn{2}{|c|}{3 sample (1/5), \% } \\
\hline & intra & extra & intra & intra & extra & intra \\
\hline Paraffins & 62.2 & 21.2 & 52.85 & 26.3 & 41.94 & 24.75 \\
\hline Unfused naphthenes & 11.81 & 20.88 & 11.86 & 20.86 & 11.31 & 18.9 \\
\hline Condensed naphthenes with 2rings & 7.82 & 20.9 & 11.87 & 18.32 & 15.49 & 22.52 \\
\hline $\begin{array}{l}\text { Condensed naphthenes and } \\
\text { naphthenes with } 3 \text { rings }\end{array}$ & 1.08 & 16.69 & 2.87 & 16.13 & 6.45 & 13.93 \\
\hline Benzene & 0.97 & 4.24 & 2.06 & 4.27 & 3.08 & 3.69 \\
\hline Naphthenobenzenes & 0.87 & 2.18 & 1.69 & 0.67 & 2.26 & 1.71 \\
\hline Dinaftenobenzenes & 0.24 & 0.24 & 0.38 & 0.02 & 0.65 & 0.12 \\
\hline Naphthalenes & 8.09 & 3.04 & 7.64 & 3.72 & 6.86 & 3.85 \\
\hline Acenaphthene & 2.33 & 2.25 & 2.27 & 2.43 & 2.46 & 2.03 \\
\hline Fluorenes & 5.2 & 9.03 & 7.37 & 5.38 & 10.81 & 8.28 \\
\hline Phenanthrenes & 0 & 0 & 0 & 1.89 & 0 & 0.22 \\
\hline
\end{tabular}

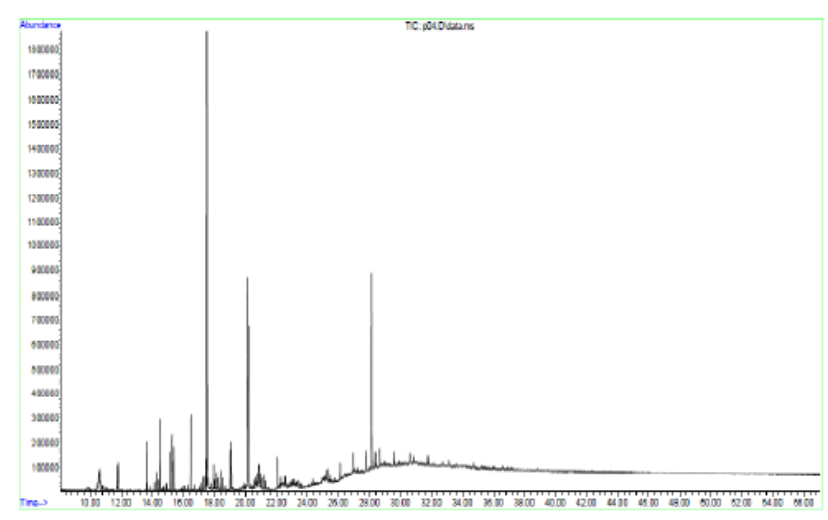

Fig. 5. Chromatogram of intracellular hydrocarbons, emitted from sample B. braunii in the natural water media of Balkhash Lake (Sample 1).

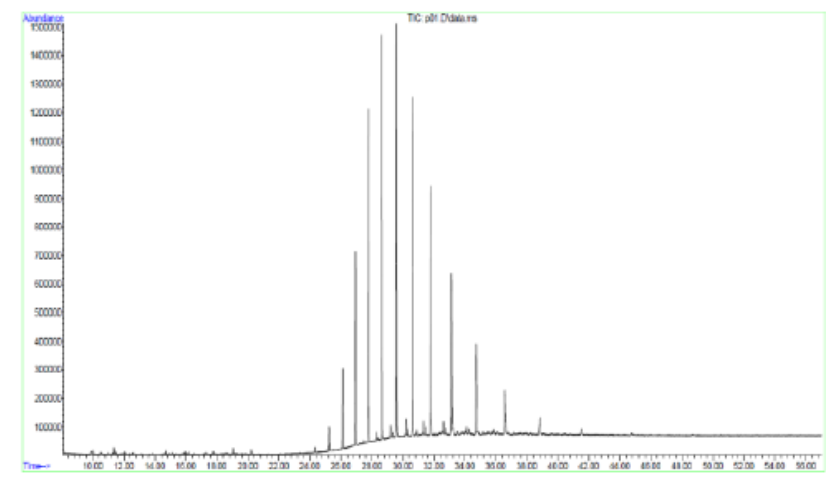

Fig. 6. Chromatogram of extracellular hydrocarbons, emitted from sample B. braunii in the natural water media of Balkhash Lake (Sample 1).

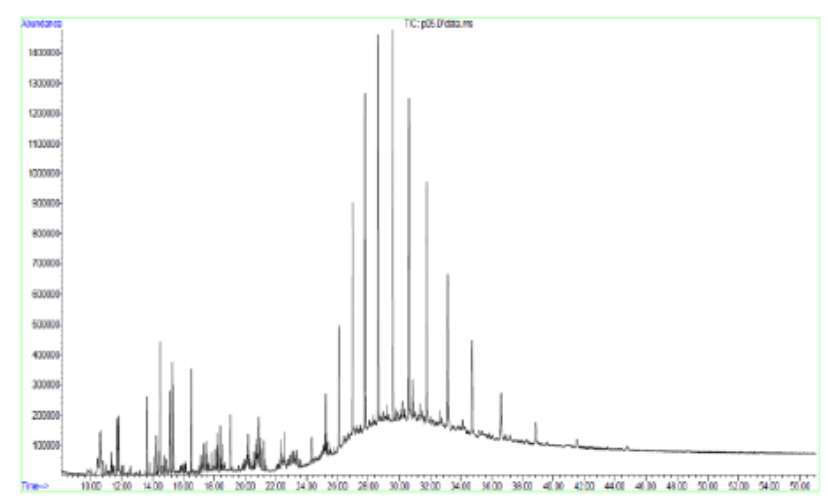

Fig. 7. The chromatogram of intracellular hydrocarbons emitted from sample B. braunii in the natural water media of Balkhash Lake, with1/2 dilution (Sample 2).

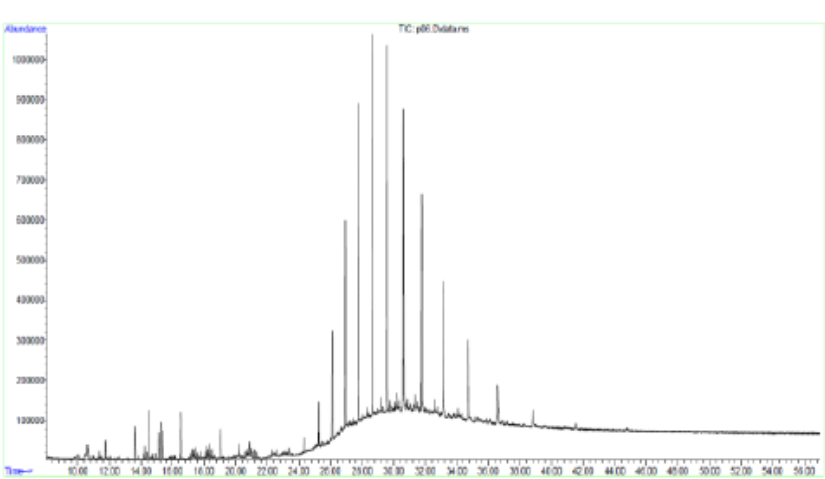

Fig. 8. The chromatogram of intracellular hydrocarbons emitted from sample B. braunii in the natural water media of Balkhash Lake, 1/5 dilution (Sample 3).

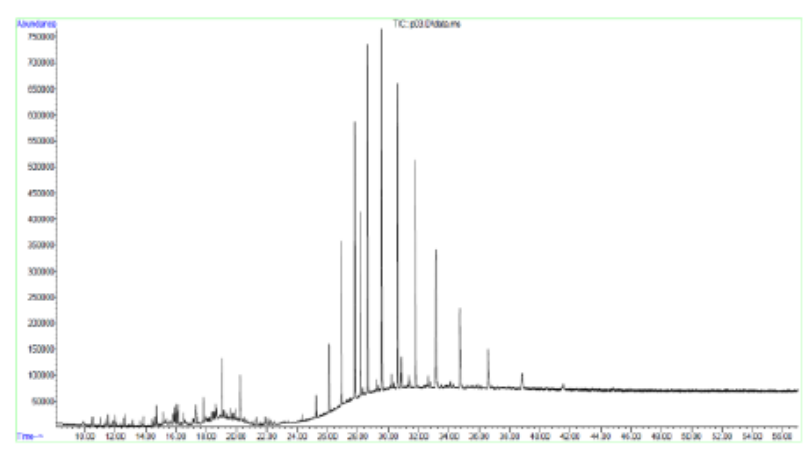

Fig. 9. The chromatogram of extracellular hydrocarbons emitted from sample B. braunii in the natural water media of Balkhash Lake, with1/2 dilution (Sample 2).

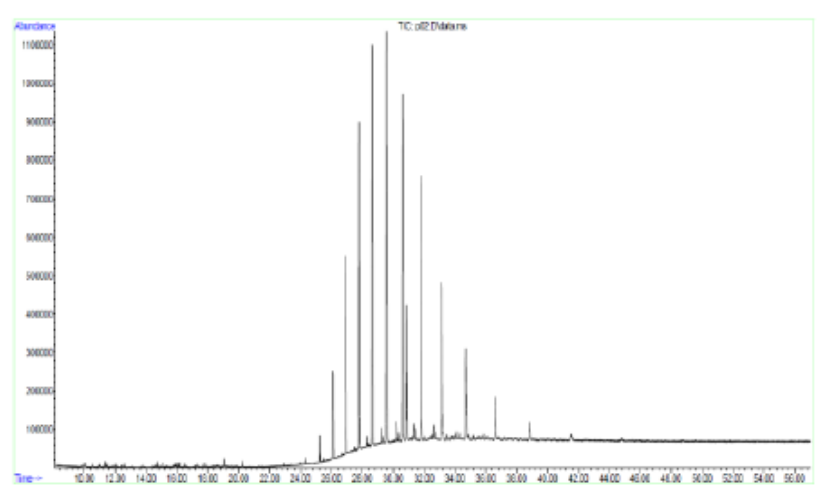

Fig. 10. The chromatogram of extracellular hydrocarbons emitted from sample B. braunii in the natural water media of Balkhash Lake, 1/5dilution (Sample 3). 


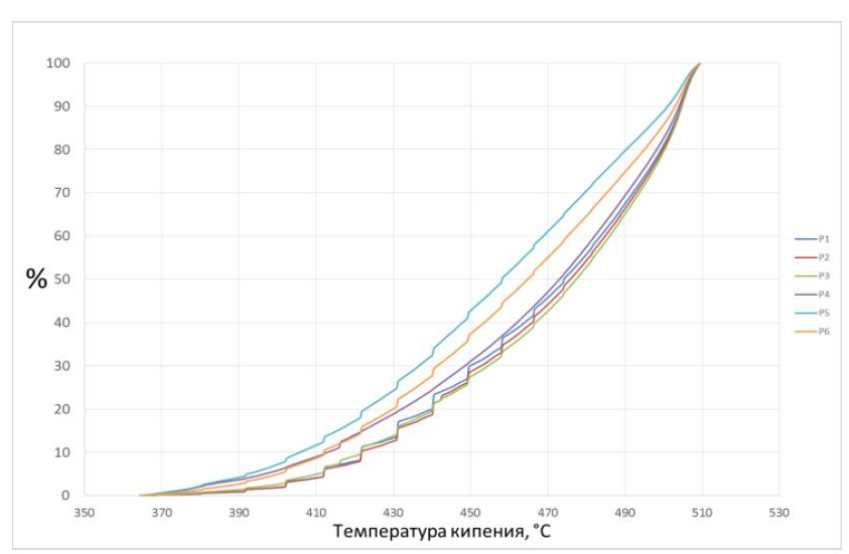

Fig. 11. Diagram for boiling of hydrocarbons, contained in the samples.

By means of the specialized software and the method of simulation distillation, intervals for boiling petroleum products were determined, using the relationship between the retention time and boiling point of the mixture components. Method meets ASTM D2887 "Standard Method for testing distribution of boiling limits of petroleum fractions using GC". Results are presented in Fig. 13 as a relationship between boiling temperature and the percentage composition of a sample eluiting from the column.

Simulated distillation method was used to characterize petroleum fractions and products, since it was able to quickly determine the distribution of their boiling range. Samples were analyzed in the nonpolar chromatographic column, which separates the hydrocarbons in the order of their boiling points.

The conducted analysis of the samples showed that samples contain hydrocarbons that correspond to the nalkanes C21-C38.

\section{CONCLUSION}

Thus, the study of the material of Botryococcus braunii culture, allocated by us from the Alakul Bay of Balkhash Lake on the liquid nutrient natural medium, made it possible to allocate Algological pure culture of microalgae

Botryococcus braunii Balkashicus. The obtained culture was used to develop conditions for cultivation a biomass there from, determination of its composition, allocation and analysis of hydrocarbons and lipids. The ability of the selected cultures to synthesize liquid hydrocarbons and fatty acids was revealed. The constitution of the lipid composition of microalgae Botryococcus braunii from the Alakol Bay of Balkhash Lake was established. Fatty acid composition of intracellular and extracellular lipids represented by saturated: mono-:diene-fattyacids of C24C12 composition in the ratio of $32: 18: 38$, respectively, indicating the potential to use this microalgaeas raw material for biodiesel.

Chromatography mass-spectral analysis provided the hydrocarbon composition of the obtained biomass, represented mainly by n-alkanes $\mathrm{C}_{21}-\mathrm{C}_{38}$. Depending on the composition of the medium, aliphatic hydrocarbons amounted to $41-62 \%$ of their total number. It was revealed that the production of extracellular hydrocarbons from algae under consideration is 2-3 times higher than that of intracellular, depending on the content of the medium.

Therefore, the present study confirmed the prospect of development and use of industrial-scale production of next generation biofuels from a unique natural raw materials microalgae Botryococcusbraunii, powerful colonies of which grow on the Alakol Bay of Balkhash Lake. Further studies are being conducted in the direction of the development of optimal conditions forcultivation in the nutrient media, contributing for productive production of biomass for processing it into biofuel products.

\section{ACKNOWLEDGMENT}

The research is conducted as part of the Ministry of Education and Science of the Republic of Kazakhstan' program of grant funding for scientific research under priority: Sources of Renewable Energy

\section{REFERENCES}

[1] E. Suali and R. Sarbatly, "Conversion of microalgae to biofuel," Renewable and Sustainable Energy Reviews, no. 16, pp. 4316-4342, 2012.

[2] J. N. Rosenberg, A. G. Oyler, L. Wilkinson, and M. J. Betenbaugh, "A green light for engineered algae: Redirecting metabolism to fuel a biotechnology revolution," Curr. Opin. Biotechnol, vol. 19, pp. 430436, 2008.

[3] N. Biondi and M. Tredici, "Algae and aquatic biomass for a sustainable production of $2^{\text {nd }}$ generation biofuels," Taxonomy, Biology and Biotechnology, pp. 78-82, 2009.

[4] P. Metzger, C. Berkaloff, E. Casadevall, and A. Coute, "Alkadieneproducing and botryococcene-producing races of wild strains of Botryococcus braunii," Phytochemistry, no. 24, pp. 2305-2312, 1985.

[5] P. Metzger, B. Allard, E. Casadevall, C. Berkaloff, and A. Couté, "Structure and chemistry of a new chemical race of Botryococcus braunii that produces lycopadiene, a tetraterpenoid hydrocarbon," $J$. Phycol., no. 26, pp. 258-266, 1990.

[6] M. Glikson, K. Lindsay, and J. Saxby, "Botryococcus - a planktonic green-alga, the source of petroleum through the ages - transmission electron microscopical studies of oil shales and petroleum source rocks," Org. Geochem, no. 14, pp. 595-608, 1989.

[7] T. L. Weiss et al., "Colony organization in the green alga botryococcus braunii (race b) is specified by a complex extracellular matrix," Eukaryotic Cell, pp. 1424-1440, 2012.

[8] P. Metzger, B. Allard, E. Casadevall, C. Berkaloff, and A. Couté, "Structure and chemistry of a new chemical race of Botryococcus braunii that produces lycopadiene, a tetraterpenoid hydrocarbon," $J$. Phycol., no. 26, pp. 258-266, 1990.

[9] P. Metzger, M. N. Rager, and L. C. Botryolins, "A and B, two tetramethylsqualene triethers from the green microalga Botryococcus braunii," Phytochemistry, no. 59, pp. 839-843, 2002.

[10] S. Okada, I. Tonegawa, H. Matsuda, M. Murakami, and K. Yamaguchi, "Braunixanthins 1 and 2, new carotenoids from the green microalga Botryococcus braunii," Tetrahedron, no. 53, pp. 1130711316, 1997.

[11] S. Derenne et al., "Chemical structure of the organic matter in a pliocene maartype shale: Implicated Botryococcus race strains and formation pathways," Geochim Cosmochim Acta, no. 61, pp. 18791889, 1997.

[12] M. Mastalerz and J. C. Hower, "Elemental composition and molecular structure of Botryococcus alginite in westphalian cannel coals from Kentucky," Org. Geochem., no. 24, pp. 301-308, 1996.

[13] T. L. Weiss et al., "Raman spectroscopy analysis of botryococcene hydrocarbons from the green microalga Botryococcus braunii," J. Biol. Chem., no. 285, pp. 32458-32466, 2010.

[14] L. W. Hillen, G. Pollard, and L. V. Wake, "Hydrocracking of the oils of Botryococcus braunii to transport fuels," Biotechnol. Bioeng., no. 24, pp. 193-205, 1982.

[15] D. Chandrappa et al., "Isolation and characterization of hydrocarbon producing green alga Botryococcus braunii from Indian freshwater bodies," Electronic Journal of Biotechnology, no. 1, pp. 79-91, 2007.

[16] H. C. Greenwell et al., "Placing microalgae on the biofuels priority list: a review of the technological challenges," Soc. Interface., no. 7, pp. 703-726, 2010. 
[17] M. Shiho et al., "Business evaluation of a green microalgae Botryococcus braunii oil production system," Procedia Environmental Sciences, no. 15, pp. 90-109, 2012.

[18] M. Watanabe, "Future Perspective of Technology for Algal Biomass Energy," Asia biomass, no. 8, pp. 87-98, 2012.

[19] E. Achitouv, P. Metzger, M. N. Rager, and C. Largeau, "C31-C34 methylated squalenes from a Bolivian strain of Botryococcus braunii," Phytochemistry, no. 65, pp. 3159-3165, 2004.

[20] P. Metzger, M. N. Rager, and C. Largeau, "Polyacetals based on polymethylsqualene diols, precursors of algaenan in Botryococcus braunii race b," Org. Geochem., no. 38, pp. 566-581, 2007.

[21] A. Banerjee, R. Sharma, Y. Chisti, and U. C. Banerjee, "Botryococcus braunii: A renewable source of hydrocarbons and other chemicals," Critical Reviews in Biotechnology, vol. 22, no. 3, pp. 245-279, 2002.

[22] M. D. Guiry and G. M. Guiry, Algae Base, World-wide electronic publication, National University of Ireland, Galway, 2012.

[23] R. F. Cane, "Coorongite, Balkaschite and related substances - an annotated bibliography," Trans. R. Soc. Aust., no. 101, pp. 153-164, 1977.

[24] J. P. L. A. Gatellier, J. W. De Leeuw, J. S. S. Damste, S. Derenne, C. Largeau, and P. Metzger, "Comparative study of macromolecular substances of a Coorangite and cell walls of the extant alga Botryococcus Braunii," Geochimica el Cosmochimica Acta., vol. 57, pp. 2053-2068, 1993.

[25] P. Metzger and C. Largeau, "Botryococcus braunii: a rich source for hydrocarbons and related ether lipid," National Center for Biotechnology Information, vol. 66, no. 5, pp. 486-496, 2005.

[26] R. Rao, C. Dayananda, R. Sarada, T. R. Shamala, and G. A. Ravishankar, "Effect of salinity on growth of green alga Botryococcus braunii and its constituents," Bioresource Technology, no. 98, pp. 560-564, 2007.

[27] Q. B. Jian, "Hydrocarbons from algae: Impacts of temperature, light and salinity on algae growth," Rural Industries Research and Development Corporation, Australia, 2005.

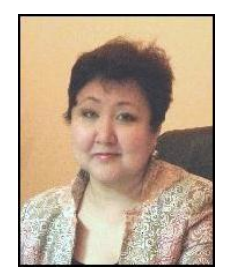

Gaukhar K. Bishimbaeva is a doctor of technical sciences, professor, associate professor of chemical engineering of Kazakh, British Technical University; chief scientific officer of Research Institute of Organic Catalysis and Electrochemistry after name D. V. Sokolsky (Almaty, Kazakhstan); Best University lecturer of Republic Kazakhstan (2006, Ministry of Education and Science of the Republic of Kazakhstan).

Her research areas include chemical technology of natural and anthropogenic sulfur feedstock; oil and gas processing; processing renewable energy sources and valuable bioproducts; processing of biofuels, electrochemical processes of corrosion protection of oil and gas equipments.

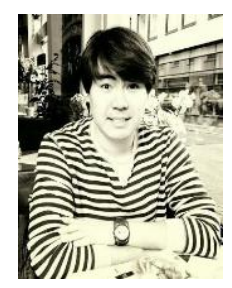

Adilzhan K. Adamgaliyev is a master student of Kazakh-British Technical University, junior researcher of Research Institute of organic catalysis and electrochemistry after name D. V. Sokolsky (Almaty, Kazakhstan).

His research areas include oil and gas processing; processing of biofuels, nuclear-chemical technology.

Sandugash K. Kazybekova is a master student of Kazakh National University, junior researcher of Institute of the Plant Biology and Biotechnology. 